\title{
Double Trouble of Severe Hyperkalemia: Syncope and No Significant ECG Changes
}

\author{
Rima Chaddad* \\ Cardiology fellow, Lebanese University, Beirut, Lebanon
}

Submission: March 03, 2021; Published: March 31, 2021

*Corresponding author: Rima Chaddad, Cardiology fellow, Lebanese University, Beirut, Lebanon

Abstract

Potassium is an important ion capable to maintain intra-extracellular electric gradient. Hyperkalemia is a common and potential lifethreatening electrolyte disorder in patients presenting to the emergency setting. Variations in the intra-extracellular ionic flow may alter cells functions, skeletal and smooth muscle contractility and electric activity of myocardial cells. Hyperkalemia can be difficult to diagnose clinically because symptoms may be vague. Patients may be asymptomatic or report non-specific symptoms such as generalized fatigue, weakness, paralysis or palpitations. Syncope is unusual neurological manifestation. An increase in serum potassium levels is followed by progressively severe electrophysiological derangements in cardiac impulse generation and conduction, which are reflected in the electrocardiogram (ECG).

Severe hyperkalemia with minimal or nonspecific ECG changes is also unusual. Here we report a 54-year-old female patient on chronic hemodialysis, who presented to our emergency department with one episode of syncope, was found to have severe hyperkalemia but without significant ecg changes and regain consciousness after urgent hemodialysis.

Keywords: Severe hyperkalemia; Syncope; Hemodialysis; ECG changes

\section{Introduction}

Hyperkalemia is a common and potential life-threatening electrolyte disorder in patients presenting to the hospital setting, with estimates ranging between $1 \%$ to $10 \%$ of hospitalized patients [1]. Mild hyperkalemia (serum potassium concentrations of 5.5-6.5 mmol/L) has been associated with tall peaked $\mathrm{T}$ waves; moderate hyperkalemia, with loss of $\mathrm{P}$ waves (6.5-7.5 $\mathrm{mmol} / \mathrm{L}$ ) and QRS complex widening (7.5-8.0 mmol/L); severe hyperkalemia (8.0-10.0 mmol/L), with ventricular arrhythmias and asystole [2]. Earlier studies suggested that potassium concentration above $7.6 \mathrm{mmol} / \mathrm{L}$ is associated with consistent ECG changes [3]. It can cause lethal arrhythmias, flaccid paralysis, and respiratory difficulty. In this study has been reported a case of life-threatening severe hyperkalemia presenting with syncope and minimal electrocardiogram changes.

\section{Case Presentation}

A 54 years old woman patient presented to the emergency room with decrease level of consciousness of 10 min duration. No associated other symptoms such as abnormal movements, urinary incontinence, uprolling eyes. No previous hx of syncope, no precending aura. She had a history of polycystic kidney and liver disease, on hemodialysis 3 times per week for 10 years go.
She is not on any antihypertensive drugs. Patient was unconscious upon presentation, responding only to painfull stimuli. In the emergency room, initial blood pressure was $110 / 60 \mathrm{mmhg}$ and pulse rate was 69 beats per min, temperature 37.3 c with a normal hemoglucotest. Other examinations were normal. The electrocardiogram showed normal sinus rhythm with regular RR interval, no QRS widening, no PR prolongation, no dropped $\mathrm{P}$ wave, minimally peaked T wave (Figure 1). Routine laboratory studies reveal severe hyperkalemia (serum potassium, $8.9 \mathrm{mmol} / \mathrm{L})$.

Serum levels of cardiac enzymes were within normal limit. She was promptly treated with $20 \mathrm{~mL}$ of intravenous $10 \%$ calcium gluconate, 10 units of intravenous insulin with 50\% dextrose and $80 \mathrm{meq} / \mathrm{l}$ sodium bicarbonate intravenously and patient started to regain her consciousness. Then, urgent hemodialysis session was performed for $2 \mathrm{~h}$ through an right AV fistula.

After $2 \mathrm{~h}$ of management, a repeat electrocardiogram was unchanged. Her vital signs were stable with blood pressure 110/65 $\mathrm{mmHg}$, and serum potassium level was $6.3 \mathrm{mmol} / \mathrm{L}$. Cardiology consultation was done, MRI brain was performed to rule out aneurysm rupture, given the history of polycystic kidney and liver 
disease, showed a small aneurysm of $3 \mathrm{~mm}$ big diameter, with no evidence of rupture or bleed was noted. EEG and Holter ECG done were also negative for seizure and arrhythmias respectively. No obvious neurologic or cardiac cause of her syncope unless for the only abnormality noted: the severe hyperkalemia.

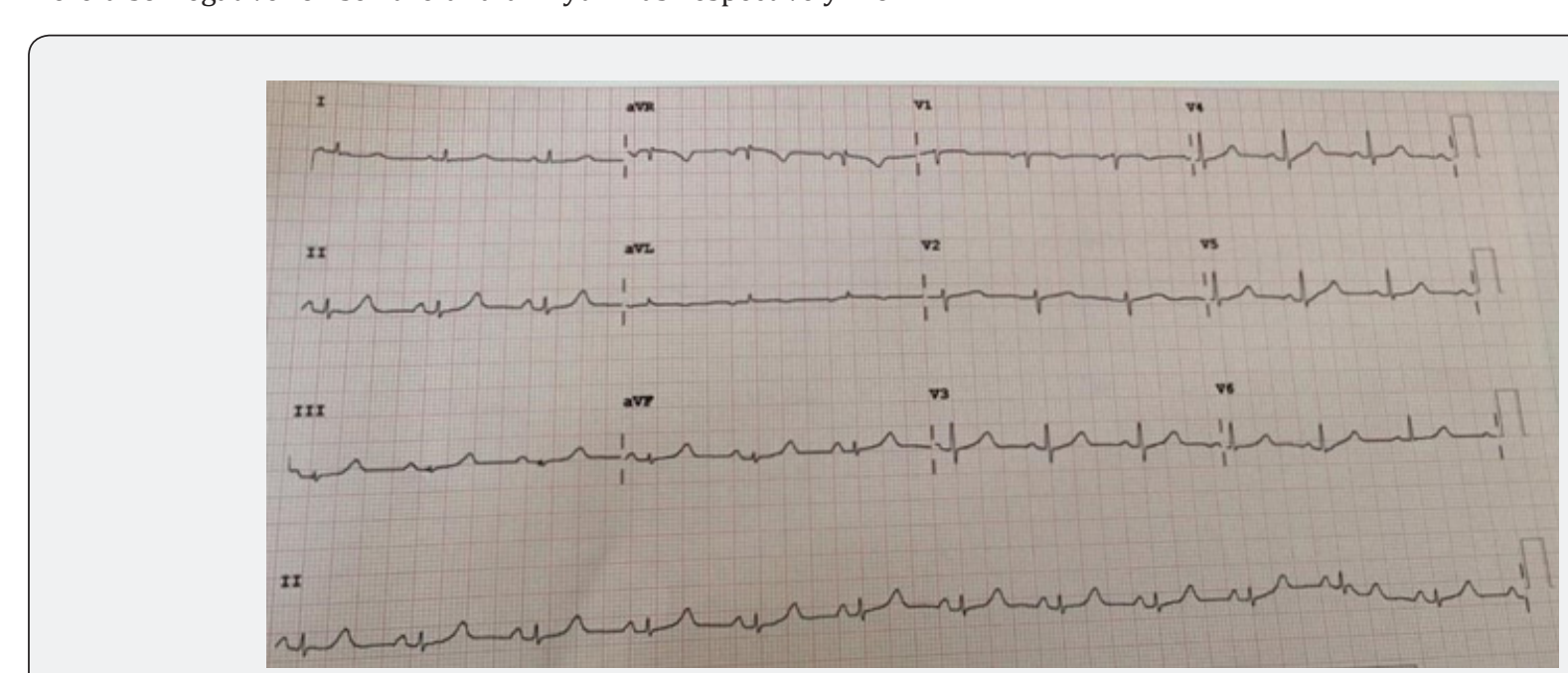

Figure 1: ECG showed sinus regular rate, with minimally peaked t wave morphology, narrow QRS normal PR and QTc interval.

\section{Discussion}

Hyperkalemia is a life-threatening electrolyte abnormality resulting ina perilouscardiacarrhythmia. Theelectrocardiographic manifestations of hyperkalemia include the peaked $\mathrm{T}$ waves generally considered the earliest sign, progressive prolongation of the PR and QRS intervals and decreased amplitude and eventual loss of the $\mathrm{P}$ waves. As serum potassium level rises, sinoatrial and atrioventricular conduction was blocked, causing escape rhythms. This is followed by widening of the QRS complex and merging with the $\mathrm{T}$ wave to form a "sine-wave" appearance, which may result in ventricular fibrillation or asystole [4]. In a clinical study, the best sensitivities and specificities for predicting hyperkalemia were reported as 0.43 and 0.86 , and the sensitivity for detecting potassium levels of more than $6.5 \mathrm{mmol} / \mathrm{L}$ was also found 0.62 which is considered to be relatively poor [5]. Consistently, Montague et al., also found that the sensitivity and specificity of ECG in diagnosing hyperkalemia was poor [6]. Typically, serum potassium levels higher than ( $\geq 8 \mathrm{mmol} / \mathrm{L}$ ) are expected to be associated with the classic ECG manifestations. However, there are contradictory reports in literature. Although rare, high levels of hyperkalemia ( $\geq 8 \mathrm{mmol} / \mathrm{L}$ ) without any significant changes in ECG were reported [7]. The underlying mechanism for why some patients do not present ECG changes is unknown. Narula et al., speculated that the rate of rise in serum potassium may also influence the development of ECG changes [7]. Also, other metabolic conditions such as acidosis, hypoxia, hyponatremia, and hypocalcemia may increase sensitivity of the heart to hyperkalemia. Although hyperkalemic paralysis has been reported, it represents a rare event. In these patients hyperkalemia was likely due to chronic renal failure associated with spironolactone therapy. Spironolactone induces hyperkalemia and a number of cases of iatrogenic hyperkalemic paralysis has been reported [8]. But syncope was not mentioned in any neurological complication of severe hyperkalemia. In our Case, despite severe hyperkalemia $(8.9 \mathrm{mmol} / \mathrm{L})$, typical electrocardiographic features were absent and unusual presentation of syncope attributed to her elevated level of serum potassium.

\section{Conclusion}

Hyperkalemia can result in life-threatening cardiac arrhythmias and patients with underlying renal impairment would be predisposed to its development. Prompt and aggressive management with medical therapy and hemodialysis could be life-saving in patients with severe hyperkalemia presented with marked arrhythmia and hemodynamic instability but it is not always the case. Cardiac and neurologic manifestations are also important. It is not the typical presentation all the time. In, conclusion, the present case shows that ECG changes may not always accompany severe changes in potassium levels and syncope could be one of the rarest manifestations of severe hyperkalemia in the absence of other causes. Further studies are needed to investigate the mechanisms between hyperkalemia and onset of ECG changes, and hyperkalemia with syncope.

\section{References}

1. Acker CG, Johnson JP, Palevsky PM, Greenberg A (1988) Hyperkalemia in hospitalized patients: causes, adequacy of treatment, and results of an attempt to improve physician compliance with published therapy guidelines. Arch Intern Med 158(8): 917-924.

2. Gogas BD, et al. (2011) Instantaneous electrocardiographic changes and transient sinus rhythm restoration in severe hyperkalemia. Int J Cardiol 148: e40-e42. 
3. Tarail R (1948) Relation of abnormalities in concentration of serum potassium to electrocardiographic disturbances. Am J Med 5(6): 828837

4. Mattu A, Brady WJ, Robinson DA (2000) Electrocardiographic manifestations of hyperkalemia. Am J Emerg Med 18(6): 721-729.

5. Wrenn KD, Slovis CM, Slovis BS (1991) The ability of physicians to predict hyperkalemia from the ECG. Ann Emerg Med 20(11): 12291232.
6. Montague BT, Ouellette JR, Buller GK (2008) Retrospective review of the frequency of ECG changes in hyperkalemia. Clin J Am Soc Nephrol 3(2): 324-330.

7. Narula AS HA (2005) Severe hyperkalemia with normal electrocardiogram Indian J [5] Nephrol 15(Supplement): S34-S36.

8. Richardson GO, Sibley JC (1953) Flaccid quadriplegia associated with hyperkalemia. Can Med Assoc J 69(5): 504-506.

This work is licensed under Creative

Commons Attribution 4.0 License

DOI: 10.19080/JOCCT.2021.16.555949

\section{Your next submission with Juniper Publishers will reach you the below assets}

- Quality Editorial service

- Swift Peer Review

- Reprints availability

- E-prints Service

- Manuscript Podcast for convenient understanding

- Global attainment for your research

- Manuscript accessibility in different formats

( Pdf, E-pub, Full Text, Audio)

- Unceasing customer service

Track the below URL for one-step submission https://juniperpublishers.com/online-submission.php 